\title{
Occurrence and Severity of White Striping in Broilers Until 50d of Age Fed with High and Low-Energy Diets: Body Weight, Histopathological Changes and Meat Quality
}

\author{
Kindlein L ${ }^{1 *}$, Ferreira TZ1 , Driemeier $D^{1}$, Nascimento VP1, Vieira SL1, Moraes LE², King A $^{2}$ and Sainz RD² \\ ${ }^{1}$ Federal University of Rio Grande do Sul, Av. Bento Gonçalves, 8834, Agronomia, Porto Alegre, RS, 91540-000, Brazil \\ ${ }^{2}$ Department of Animal Science, University of California, One Shields Avenue, Davis, CA, 95616-8521, USA
}

\begin{abstract}
White striping (WS) is a condition characterized by the occurrence of white striations parallel to the muscle fibers on breast, thigh, and tender muscle of broilers. This study was aimed to evaluate the occurrence and severity of white striping and histopathological changes in breast fillets from 10 to $50 \mathrm{~d}$ broilers disregarding the effect of diet. Birds $(n=572)$ were randomly assigned to a high(HED) or low-energy (LED) diet (11 replicates of 26 birds/ dietary treatment) and were processed at 10, 20, 30, 40 and $50 \mathrm{~d}$ of age to evaluate occurrence of white striping, BW, histological analysis, and meat quality. The results showed that at $10 \mathrm{~d}$ of age, $2.27 \%$ of the birds showed some degree of WS and at 20 and $30 \mathrm{~d}$ of age the occurrence of WS (\%) was higher in birds fed HED than birds fed LED diets. There was no differences $(P>0.05)$ in the $L^{*}, a^{*}$, and $b^{*}$ values for meat or among different degrees of WS as well as between dietary treatments; however, carcass characteristics varied by age or carcass weight. Histologically, the severity of WS causes changes in myofibers, with muscle fibers showing sarcoplasmic reticulum vacuolization, a higher intercapillary distance and a reduced capillary to fiber ratio, suggesting loss of integrity of the cell structure, that was seen in birds fed both diets (low and high nutrient densities) after $30 \mathrm{~d}$ of age and lower oxygenation.
\end{abstract}

Keywords: Breast muscle; Energy; Myopathy; Oxygenation

\section{Introduction}

The high productive of poultry as a result of a constant increase in the world demand for white meat with a intensive genetic selection for fast growth rate and high breast yield, have been spurring the broiler industry towards practices that increase its production [1-3], and these factors may induce metabolic stresses that can negatively impact meat quality [4-6]. More recently, high growth rate and high breast yield have been associated with the occurrence of other myopathies affecting pectoralis major and other muscles, i.e., white striping $[7,8]$. White Striping (WS) is visually characterized by the white lines of intramuscular deposits in raw meat seen parallel to the muscle fibers mainly in breast, tenders, and certain thigh muscles [9]. Histologic reports of WS demonstrated alterations with loss of cross striations between muscle fibers, variability in muscle fiber size, floccular/vacuolar degeneration and lysis of fibers, mild mineralization, mononuclear cell infiltration, lipidosis, instersticial inflammation, and fibrosis $[9,10]$.

Feeding strategies may be used to control de occurrence of myopathies in broiler chickens: low-energy diets reduce both growth rate and the occurrence of white striping [11], however the correlation between the occurrence of this myopathy and growth rate/final live weight and/or breast yield in current broiler genotypes under commercial intensive conditions has been proposed but not fully demonstrated [3]. Bailey et al. [12] also described that the analysis of data from two broiler lines that differed in terms of selection for breast yield showed that there is also a strong non-genetic component for all breast muscle myopathy traits. So, these factors may induce metabolic stresses that can negatively impact meat quality [4-6]. Thus, evaluation of changes in muscle fibers is crucial for elucidation of the pathological basis for white striping [13]. Also, the occurrence of severe degrees of these modern myopathies in broiler breast fillets reduces the quality and acceptance of both raw as well as cooked meat and meat products [14]. The present study was conducted to determine the occurrence and severity of white striping and histopathological changes in breast fillets from 10 to $50 \mathrm{~d}$ broilers disregarding the effect of diet.

\section{Materials and Methods}

\section{Experimental design}

A total of 572 1-d-old Cobb X Cobb 500 male broiler chicks were assigned to two dietary treatments: high (HED; 3,000 to 3,300 kcal ME/ $\mathrm{kg}$ and 24.19 to $19.56 \% \mathrm{CP}$ ) and low nutrient density diet sequences (LED; 2,900 to $3,050 \mathrm{kcal} \mathrm{ME} / \mathrm{kg}$ and 20.44 to $18.37 \% \mathrm{CP}$ ). The HED and LED diet sequences were formulated based on the suggested needs for male broilers with high and low performance, respectively [15] using corn, soybean meal and toasted soybeans (Tables 1 and 2). Birds were fed on an ad libitum basis in four phases, consisting of pre-starter ( 1 to $7 \mathrm{~d}$ ), starter ( 8 to $21 \mathrm{~d}$ ), grower ( 22 to $35 \mathrm{~d}$ ), and finisher ( 36 to $50 \mathrm{~d}$ ). All diets were fortified with complete vitamin and trace mineral mixes obtained from commercial sources. The study was conducted in a completely randomized design having 2 treatments and 11 replicates of 26 birds at the beginning of the study. Birds had ad libitum access to feed and water. Temperature in the first week of life was $32^{\circ} \mathrm{C}$, and then decreased to $25^{\circ} \mathrm{C}$ until the end of experiment. Birds were kept on 18 hours of light throughout the study. All pens were checked for sick and dead birds on a daily basis. Two birds per pen were randomly selected from each pen and processing at 10, 20,30, 40 and $50 \mathrm{~d}$-ofage. All procedures throughout the current study were approved by the Ethics Committee on Animal Use of the Federal University of Rio Grande do Sul.

*Corresponding author: Kindlein L, Veterinary Faculty, Federal University of Rio Grande do Sul, Av. Bento Gonçalves, 8834, Agronomia, Porto Alegre, RS, 91540 000, Brazil, Tel: +555133089996; E-mail: liris.kindlein@ufrgs.br

Received September 28, 2017; Accepted October 13, 2017; Published October 15,2017

Citation: Kindlein L, Ferreira TZ, Driemeier D, Nascimento VP, Vieira SL, et al. (2017) Occurrence and Severity of White Striping in Broilers Until 50d of Age Fed with High and Low-Energy Diets: Body Weight, Histopathological Changes and Meat Quality. J Vet Sci Technol 8: 478. doi: 10.4172/2157-7579.1000478

Copyright: (c) 2017 Kindlein L, et al. This is an open-access article distributed unde the terms of the Creative Commons Attribution License, which permits unrestricted use, distribution, and reproduction in any medium, provided the original author and source are credited. 
Citation: Kindlein L, Ferreira TZ, Driemeier D, Nascimento VP, Vieira SL, et al. (2017) Occurrence and Severity of White Striping in Broilers Until 50d of Age Fed with High and Low-Energy Diets: Body Weight, Histopathological Changes and Meat Quality. J Vet Sci Technol 8: 478. doi: $10.4172 / 2157-7579.1000478$

Page 2 of 8

\begin{tabular}{|c|c|c|c|c|c|c|c|c|}
\hline \multicolumn{9}{|c|}{ Diet nutrient densities ${ }^{1}$} \\
\hline \multirow{2}{*}{$\begin{array}{c}\text { Ingredients, } \mathbf{g} / \mathbf{k g} \text { or as } \\
\text { noted }\end{array}$} & \multicolumn{4}{|c|}{ High-energy } & \multicolumn{4}{|c|}{ Low-energy } \\
\hline & 1 & 2 & 3 & 4 & 1 & 2 & 3 & 4 \\
\hline Corn $(7.8 \% \mathrm{CP})$ & 47.7 & 54.1 & 55.7 & 58.5 & 62.2 & 62 & 65 & 68 \\
\hline Soybean meal $(45 \% \mathrm{CP})$ & 44.2 & 37.8 & 35.6 & 32.1 & 33.4 & 33.7 & 31 & 28.23 \\
\hline Soybean oil & 4.16 & 4.46 & 5.58 & 6.52 & 0.22 & 0.91 & 1 & 1.15 \\
\hline Sodium Bicarbonate & 0.03 & 0.05 & 0.04 & 0.13 & 0.41 & 0.12 & 0.13 & 0.19 \\
\hline Hiphos GT & 0.01 & 0.01 & 0.01 & 0.01 & 0.01 & 0.01 & 0.01 & 0.01 \\
\hline Dicalcium phosphate & 1.23 & 1.02 & 0.82 & 0.64 & 1.31 & 1.04 & 0.85 & 0.65 \\
\hline Limestone & 1.25 & 1.16 & 0.94 & 0.86 & 1.25 & 1.16 & 0.95 & 0.87 \\
\hline Salt & 0.57 & 0.5 & 0.46 & 0.34 & 0.3 & 0.45 & 0.39 & 0.3 \\
\hline MHA, $84 \%$ & 0.44 & 0.39 & 0.37 & 0.33 & 0.35 & 0.26 & 0.25 & 0.21 \\
\hline L-Lysine $78 \%$ & 0.18 & 0.2 & 0.2 & 0.21 & 0.22 & 0.08 & 0.11 & 0.11 \\
\hline L-Threonine $98.5 \%$ & 0.07 & 0.1 & 0.09 & 0.09 & 0.06 & 0.02 & 0.02 & 0.01 \\
\hline Min. and Vit. Premix ${ }^{1}$ & 0.15 & 0.15 & 0.15 & 0.15 & 0.15 & 0.15 & 0.15 & 0.15 \\
\hline Choline chloride $60 \%$ & 0.04 & 0.06 & 0.06 & 0.06 & 0.08 & 0.07 & 0.07 & 0.08 \\
\hline Monensin sodium ${ }^{3}, \mathrm{ppm}$ & 100 & 100 & 100 & 100 & 100 & 100 & 100 & 100 \\
\hline Flavomycin ${ }^{4}, \mathrm{ppm}$ & 25 & 25 & 25 & 25 & 25 & 25 & 25 & 25 \\
\hline
\end{tabular}

${ }^{1}$ Pre-starter, d 1-7; 2, starter, d 8-21; 3, grower, d 22-35; and 4, finisher, d $36-50$ met or exceeded the Nutrient Requirement of Poultry according to Rostagno et al.

${ }^{2}$ Composition per kg of feed: retinyl acetate, 2,400 mg; cholecalciferol, $0.005 \mathrm{mg}$; alpha-tocopherol acetate $30 \mathrm{mg}$; menadione, $2 \mathrm{mg}$; thiamine, $2 \mathrm{mg}$; riboflavin, $6 \mathrm{mg}$ pyridoxine, $2.5 \mathrm{mg}$; cyanocobalamine, $0.012 \mathrm{mg}$, panthothenic acid, $15 \mathrm{mg}$; niacin, $35 \mathrm{mg}$; folic acid, $1 \mathrm{mg}$; biotin, $0.08 \mathrm{mg}$; iron, $40 \mathrm{mg}$; zinc, $80 \mathrm{mg}$; manganese, $80 \mathrm{mg}$; copper, $10 \mathrm{mg}$; iodine, $0.7 \mathrm{mg}$; selenium, $0.3 \mathrm{mg}$.

${ }^{3}$ Poucox® 40 .

${ }^{4}$ Flavomycin 880 .

Table 1: Formulations of experimental diets.

\begin{tabular}{|c|c|c|c|c|c|c|c|c|}
\hline \multirow{3}{*}{$\begin{array}{c}\text { Energy and } \\
\text { nutrients, \% or as } \\
\text { noted }\end{array}$} & \multicolumn{8}{|c|}{ Diet nutrient densities $^{1}$} \\
\hline & \multicolumn{4}{|c|}{ High-energy } & \multicolumn{4}{|c|}{ Low-energy } \\
\hline & 1 & 2 & 3 & 4 & 1 & 2 & 3 & 4 \\
\hline $\mathrm{AME}_{\mathrm{n}}^{2}, \mathrm{kcal} / \mathrm{kg}$ & 3,000 & 3,100 & 3,200 & 3,300 & 2,900 & 2,950 & 3,000 & 3,050 \\
\hline $\mathrm{CP}$ & 24.19 & 21.81 & 20.95 & 19.56 & 20.44 & 20.38 & 19.43 & 18.37 \\
\hline $\mathrm{Ca}$ & 1.05 & 0.95 & 0.82 & 0.74 & 1.05 & 0.95 & 0.82 & 0.74 \\
\hline Av. $P$ & 0.5 & 0.45 & 0.41 & 0.37 & 0.5 & 0.45 & 0.41 & 0.37 \\
\hline $\mathrm{Na}$ & 0.25 & 0.23 & 0.21 & 0.19 & 0.25 & 0.23 & 0.21 & 0.19 \\
\hline $\mathrm{K}$ & 0.95 & 0.85 & 0.81 & 0.76 & 0.79 & 0.8 & 0.76 & 0.71 \\
\hline $\mathrm{Cl}$ & 0.43 & 0.4 & 0.37 & 0.31 & 0.29 & 0.35 & 0.32 & 0.27 \\
\hline $\mathrm{DEB}, \mathrm{mEq} / \mathrm{kg}$ & 230 & 205 & 195 & 190 & 230 & 205 & 195 & 190 \\
\hline Dig. Lys ${ }^{3}$ & 1.37 & 1.23 & 1.18 & 1.1 & 1.15 & 1.05 & 1.01 & 0.94 \\
\hline Dig. Met & 0.7 & 0.63 & 0.6 & 0.56 & 0.58 & 0.51 & 0.49 & 0.45 \\
\hline Dig. Met+Cys & 1.03 & 0.92 & 0.89 & 0.83 & 0.86 & 0.79 & 0.76 & 0.7 \\
\hline Dig. Thr & 0.89 & 0.84 & 0.8 & 0.75 & 0.75 & 0.71 & 0.69 & 0.64 \\
\hline Dig. Val & 1.03 & 0.92 & 0.89 & 0.82 & 0.86 & 0.87 & 0.83 & 0.78 \\
\hline Dig. Ile & 0.96 & 0.85 & 0.82 & 0.76 & 0.79 & 0.8 & 0.75 & 0.71 \\
\hline Dig. Leu & 1.84 & 1.69 & 1.64 & 1.55 & 1.62 & 1.63 & 1.58 & 1.51 \\
\hline
\end{tabular}

11, pre-starter, d 1-7; 2, starter, d 8-21; 3, grower, d 22-35; 4, and finisher, d 36-50 met or exceeded the Nutrient Requirement of Poultry according to Rostagno et al. ${ }^{2} \mathrm{AME}$, Apparent Metabolizable Energy.

${ }^{3}$ Amino acid: Iysine (digestible): Met+Cys $75 \%$, Tre $65 \%$, Val $75 \%$, Ile $70 \%$, Arg $108 \%$, Trp $17 \%$.

${ }^{4}$ Flavomycin ${ }^{\circledR} 80$.

Table 2: Compositions of experimental diets.

Birds were fasted for $6 \mathrm{~h}$, individually weighted before electrical stunning ( $45 \mathrm{~V}$ for $3 \mathrm{~s}$ ), bled for $3 \mathrm{~min}$ after carotid and jugular veins cut, scalded at $60^{\circ} \mathrm{C}$ for $45 \mathrm{~s}$, and mechanically defeathered. Carcasses were manually eviscerated and then statically chilled in slush ice for $3 \mathrm{~h}$ before processing. Breast fillets were manually deboned from the carcasses and WS evaluations were immediately performed on boneless skinless breast according to Kuttappan et al. [7] as: normal, no striping (NORM) samples, whereas those with striations were moderate (MOD, $<1$-mm-thick striations) or severe (SEV, >1-mm-thick striations). Carcass yield was expressed as a percentage of live weight and breast yield was expressed as a percentage of eviscerated carcass weight.

\section{Tissue sample processing}

All the muscle sections were cut parallel to the direction of muscle fibers and fixed in $10 \%$ buffered neutral formalin. Histopathology samples were dehydrated with increasing concentrations of ethanol, cleared, infiltrated, and embedded in paraffin. Five tissue cross sections were prepared from each muscle sample collected. Blocks were cut into serial sections of $3 \mu \mathrm{m}$ thickness using a microtome (Leica RM 2125RT, Leica Biosystems, Nussloch, Germany) and stained with hematoxylin and eosin (H\&E) to evaluate the general morphology of the tissues. Ten slides for each muscle sample were examined under a light microscope (Leica ICC50 HD, Leica Biosystems, Nussloch, Germany) at 10X objective and capillary density $(\mathrm{CP})$ at $1000 \mathrm{X}$. The means of capillary to 
Citation: Kindlein L, Ferreira TZ, Driemeier D, Nascimento VP, Vieira SL, et al. (2017) Occurrence and Severity of White Striping in Broilers Until 50d of Age Fed with High and Low-Energy Diets: Body Weight, Histopathological Changes and Meat Quality. J Vet Sci Technol 8: 478. doi: 10.4172/2157-7579.1000478

Page 3 of 8

fiber ratio (C:F) was calculated by the ratio of the number of capillaries per area divided by the number of fibers in a given area and the intercapillary distances (IcD) were calculated using Krogh's cylinder method, because its radius, $r_{k} \sqrt{ } 1 /(\pi \times$ capillary density) is half of the mean intercapillary distance $[16,17]$. Three veterinary pathologists scored histological lesions separately.

\section{Measured responses}

Muscle $\mathrm{pH}$ at time $0\left(\mathrm{pH}_{0}\right)$ or $24 \mathrm{~h}$ post-mortem $\left(\mathrm{pH}_{24}\right)$ were measured using a Sensoglass spear tip probe and meter (Lutron-208, Lutron Electronic Enterprise CO., Taiwan), which was inserted in the inner portion of the muscle. The color of the pectoral muscles was assessed in triplicate with a CIELAB ${ }^{\star}$ System ( $\mathrm{L}^{\star}$ : lightness, $\mathrm{a}^{*}$ : red, and $\mathrm{b}^{\star}$ : yellow) using a Minolta colorimeter (model 410R, Konica Minolta, Ramsey, NJ). Each breast sample was packed in a heat-resistant Perflex11 Film Viskase plastic bag and heated in water baths at $80^{\circ} \mathrm{C}$ for $60 \mathrm{~min}$ [18] until an internal temperature of $71 \pm 2^{\circ} \mathrm{C}$ was reached [19]. Three cores $(1.27 \mathrm{~cm}$ diameter) were manually removed from each fillet parallel to the muscle fibers using a punch tool adapted to an electric drill. The shear force of $2.5 \mathrm{~cm}$ thick samples was measured using a TAXT-2i texture analyzer coupled with a Warner-Bratzler blade (Warner-Bratzler Shear Force; WBSF, G-R Manufacturing Co., Manhattan, KS). Breast samples were cored and sheared before $\left(\mathrm{SF}_{\text {raw }}\right)$ and after cooking $\left(\mathrm{SF}_{\text {cooked }}\right)$ and the average of six readings for each was used as the final value (expressed in $\mathrm{kgF} / \mathrm{g}$ ), according to the methodology used by Liu [20]. Due the white striations be clearly visualized on the Pectoralis major muscle in nature, for analysis to $\mathrm{SF}_{\text {raw }}$, an adaptation of methodology used by Liu [20] was adopted, why particular technique.

\section{Statistical analyses}

Occurrence of white striping: Incidence of white striping on breasts of the two dietary treatments was examined by use of a multinomial baseline logit mixed effects model. Specifically, $Y_{i j k}$ denotes the $\mathrm{k}^{\text {th }}$ categorical record $\left(\mathrm{k}=1, \ldots, \mathrm{n}_{\mathrm{ij}}\right)$ on the $\mathrm{i}^{\text {th }}$ treatment $(i=1,2)$ and $j^{\text {th }}$ pen $(j=1, \ldots, 22)$ and represents a multinomial sampling model with probabilities $\left\{\pi_{\mathrm{ijk} 1}, \pi_{\mathrm{ijk} 2}, \pi_{\mathrm{ijk} 3}\right\}$. The probabilities sum to one and represent the probabilities of being classified in one of the three categories of white striping, i.e., $\pi_{\mathrm{ijk} 1}=\mathrm{P}\left(\mathrm{Y}_{\mathrm{i} \mathrm{k}}=\mathrm{Normal}\right), \pi_{\mathrm{ijk} 2}=\mathrm{P}$ $\left(\mathrm{Y}_{\mathrm{ijk}}=\right.$ Moderate $)$ and $\pi_{\mathrm{ijk} 3}=\mathrm{P}\left(\mathrm{Y}_{\mathrm{ij \textrm {k }}}=\right.$ Severe $)$. The effects of treatment, $\mathrm{BW}$, and pen were modelled as:

$$
\log \left(\frac{\pi_{\mathrm{ij}} \mathrm{kr}}{\pi_{\mathrm{ij}} \mathrm{k} 1}\right)=\beta_{0 \mathrm{r}}+\beta_{1 r} X_{i j k}+\alpha_{i r}+\gamma_{j r}, \mathrm{r}=2,3 .
$$

where $\beta_{0 r}$ is the intercept for category $\mathrm{r}, \beta_{l r}$ is the slope for category $r$ describing the change in the log odds with an increment of one kilogram of BW, $X_{i i k}$ is the centered BW weight in kilograms, $\alpha_{i r}$ is the fixed effect of $\mathrm{i}^{\text {th }}$ dietary treatment on the log odds for category $r$ and $\gamma_{j r}$ is the random effect associated with the of $j^{\text {th }}$ bin on the log odds of category $r$. It was assumed that random effects are independent and distributed $\gamma_{j r} \square N\left(0, \sigma_{r}^{2}\right)$. The model was fitted in a Bayesian framework with the Open BUGS software [21], which was interfaced with the $\mathrm{R}$ software through the BRugs package [22]. Minimally informative priors were specified for all parameters and convergence was assessed by specifying two chains with over dispersed initial values and the monitoring of history and autocorrelation plots and the use of the Gelman-Rubin diagnostics [23]. A burn-in period of 10,000 samples was used and the inference was based on additional 500,000 samples thinned by a factor of 50 .

Effects of dietary treatments and white striping on physicochemical variables: Effects of dietary treatment and white striping on the measured physicochemical variables were investigated using the following linear mixed effects model:

$$
Y_{i j k m}=\mu+\alpha_{i}+\delta_{j}+(\alpha \delta)_{i j}+\beta X_{i j k m}+\gamma_{k}+\varepsilon_{i j k m}
$$

where $\mathrm{Y}_{\mathrm{ijkm}}$ is the $\mathrm{m}^{\text {th }}$ record $\left(\mathrm{m}=1, \ldots, \mathrm{n}_{\mathrm{ij}}\right)$ of the dependent variable measured on the $i^{\text {th }}$ dietary treatment $(i=1,2)$, $j^{\text {th }}$ level of white striping $(\mathrm{j}=1,2,3)$ and $\mathrm{k}^{\text {th }}$ pen $(\mathrm{k}=1, \ldots, 22), \mu$ is the overall mean, $\alpha_{i}$ is the fixed effect associated with the $\mathrm{i}^{\text {th }}$ dietary treatment, $\delta_{j}$ is the fixed effect associated with the $\mathrm{j}^{\text {th }}$ level of white striping, $(\alpha \delta)$ is the interaction term, $\gamma_{k}$ is the random effect associated with the $\mathrm{k}^{\text {th }}$ bin, $\beta$ is the regression coefficient for the relationship between the dependent variable and the animal BW, $\mathrm{X}_{\mathrm{ijkm}}$ is the centered $\mathrm{BW}$ weight and $\varepsilon_{\mathrm{ijkm}}$ is the error. It was assumed that random effects and errors are independent and distributed as $\gamma_{\mathrm{k}} \sim \mathrm{N}(0, \tau)$ and $\varepsilon_{\mathrm{ijkm}} \sim \mathrm{N}\left(0, \sigma^{2}\right)$ Variance functions of the fitted values were used to model the variance structure of the within-group errors when heteroscedasticity was present as described in Pinheiro and Bates [24]. Models were fitted in the R statistical software [25] with the nlme package [26]. When treatment effects were present, multiple comparisons were conducted with the multcomp package [27]. When no interactions were present, treatments were compared directly, but when interactions were present treatments were compared within each level of the other factor. The $\mathrm{P}$-value of the multiple comparisons was estimated with the single-step method [27].

\section{Results}

\section{Occurrence of white striping}

The estimated parameters of the multinomial baseline logit mixed effects model are in Table 3. Results suggest that the odds of having MOD rather than NORM white striping for the LED diet were 0.40 times the odds for the HED diet. Similarly, the odds of having SEV rather than NORM white striping for the LED diet were 0.32 times the odds for the HND diet. Moreover, results also suggested that the odds of having MOD rather than NORM white striping was multiplied by

\begin{tabular}{|c|c|c|}
\hline $\begin{array}{c}\text { Estimated } \\
\text { parameters }\end{array}$ & Estimate & 95\% Credible interval \\
\hline$\beta_{0, r=2}$ & 2.58 & $(1.50,3.82)$ \\
\hline$\beta_{0, r=3}$ & 1.79 & $(0.63,3.07)$ \\
\hline$\beta_{1, r=2}$ & 3.01 & $(2.13,4.05)$ \\
\hline$\beta_{1, r=3}$ & 3.8 & $(2.84,4.90)$ \\
\hline$\alpha_{r=2}$ & -1.05 & $(-2.10,-0.05)$ \\
\hline$\alpha_{r=3}$ & -1.31 & $(-2.52,-0.18)$ \\
\hline$\sigma_{r=2}^{2}$ & 0.11 & $(0.0008,0.6506)$ \\
\hline$\sigma_{r=3}^{2}$ & 0.04 & $(0.0006,0.3098)$ \\
\hline Odds $^{*}$ & & $(0.12,0.95)$ \\
\hline$\theta_{\text {diet, } r=2}$ & 0.4 & $(0.08,0.84)$ \\
\hline$\theta_{\text {diet, },=3}$ & 0.32 & $(17.18,133.40)$ \\
\hline$\theta_{\text {bw, }=2}$ & 23.01 & \\
\hline$\theta_{b w, r=3}$ & 51.15 & \\
\hline
\end{tabular}

$\theta_{\text {dietr }}$ represents the change in the odds of having white striping classified as $r(r=2$ for moderate or $r=3$ for severe) rather than the baseline category (normal white striping) for the low energy diet in respect to the high energy diet. Similarly, $\theta_{\text {bw }}$ represent the change in the odds for one kilogram increment in body weight.

Table 3: Estimated parameters and corresponding estimated effects on the odds, with associated $95 \%$ Credible Intervals, for the multinomial baseline mixed effects model. 
Citation: Kindlein L, Ferreira TZ, Driemeier D, Nascimento VP, Vieira SL, et al. (2017) Occurrence and Severity of White Striping in Broilers Until 50d of Age Fed with High and Low-Energy Diets: Body Weight, Histopathological Changes and Meat Quality. J Vet Sci Technol 8: 478. doi: 10.4172/2157-7579.1000478

Page 4 of 8

23.01 for each kilogram increase in BW weight. Similarly, the odds of having SEV rather than NORM white striping were multiplied by 51.15 for each kilogram increase in BW. The frequencies of occurrence of each degree of white striping with respect to BW for each diet treatment (LED and HED) are shown in Figure 1.

The graphs in Figure 1 clearly indicate that there was a reduction in the odds of occurrence of NORM samples as BW increased, confirming the report by Kuttappan et al. [11] that the occurrence of white striping was significantly related to carcass weight and yield. This research, the authors showed that the increase in growth rates result in higher incidence of this myopathy, corroborating with our results. In our study, the results showed the progression of the development of WS until $50 \mathrm{~d}$ of age, indicating that at $20 \mathrm{~d}$-age the histological changes begin in the birds.

The occurrence date of white striping (\%) showed that at $10 \mathrm{~d}$ of age only $2.27 \%$ of the animals showed some degree of WS, and these animals fed HED diet, the others did not show WS. At $20 \mathrm{~d}$ and $30 \mathrm{~d}$ of age the occurrence of white striping (\%) was higher in birds fed HED (59.09 and 77.27, respectively, $P<0.05$ ) than birds fed LED diets $(13.64$ and 68.18, respectively). At 20 days, just animals fed HED showed SEV white striping. However, after $40 \mathrm{~d}$ of age, all animals $(100 \%$, both diets) showed WS.

The average body weight of birds with $30 \mathrm{~d}$ of age showed difference $(P<0.05)$ between the two dietary treatments $(1840.00 \pm 32.66 ; 1662.27$ $\pm 43.09 \mathrm{~g}$ ). Birds fed a high-diet-fed (HED) grew more rapidly (higher growth rate) than LED diet-fed birds at 20, 30, 40 and $50 \mathrm{~d}$ of age.

These results are in accordance to other authors, that associated that the use of high-energy diets in conjunction with farming systems, allowing a low mobility of the animals and increasing slaughter ages and weights which have been employed by poultry industry may be the important factors involved in this problem $[11,28,29]$.

\section{Effects of dietary treatments and white striping on} physicochemical variables

The analysis of variance tables with F-tests and associated P-values of the general linear model hypothesis of dietary treatment and white striping associated effects are shown in Table 4.

There were significant differences in the values of $\mathrm{pH}_{0}, \mathrm{pH}_{24}, \mathrm{SF}_{\text {raw }}$ and $\mathrm{SF}_{\text {cooked }}$ at different BW and ages (Table $4, P<0.001$ ). The values of $\mathrm{pH}_{0}$ and $\mathrm{pH}_{24}$ increased with $\mathrm{BW}$, showing mean values 6.35 and 6.20, ranging from 5.22 and 5.21 to 8.73 and 6.90, respectively. However, the $\mathrm{pH}_{24}$ value in breasts of birds fed LED diets tended to be higher in MOD than NORM white striped ( $6.21 \pm 0.27$ vs. $5.72 \pm 0.29 ; P=0.09)$.

Kuttappan et al. [8] found no association between the occurrence of white striping and changes in $\mathrm{pH}$ values and the $\mathrm{pH}_{24}$ values in NORM breast in that study were similar $(5.78 \pm 0.02)$ to those found in our study. Low $\mathrm{pH}_{24}$ values $(<5.7)$ can be indicative of poor meat quality [30]. Woelfel et al. [31] found mean ultimate $\mathrm{pH}_{24}$ values of 5.76 for pale meat and 6.07 for normal meat, values that are similar to the mean values found in the present study, in which the NORM broiler breast samples were in the $\mathrm{pH}_{24}$ range of 5.21 to 6.30 .

Velleman et al. [32] found that feed restricted birds had decreased BW gain from $1 \mathrm{~d}$ post hatch through $28 \mathrm{~d}$ of age. Furthermore, the Pectoralis major muscle weight was significantly reduced by the feed restriction. In contrast to our study, those authors concluded that for both the body and Pectoralis major muscle weights there was no interaction between age and treatment.

There were no differences in the $\mathrm{L}^{*}, \mathrm{a}^{*}$ and $\mathrm{b}^{*}$ values of breast meat samples with different degrees of white striping, as well as of breasts of birds fed different diets. Normal $L^{*}$ values of raw broiler breast

\section{Low nutrient density diet (LND)}

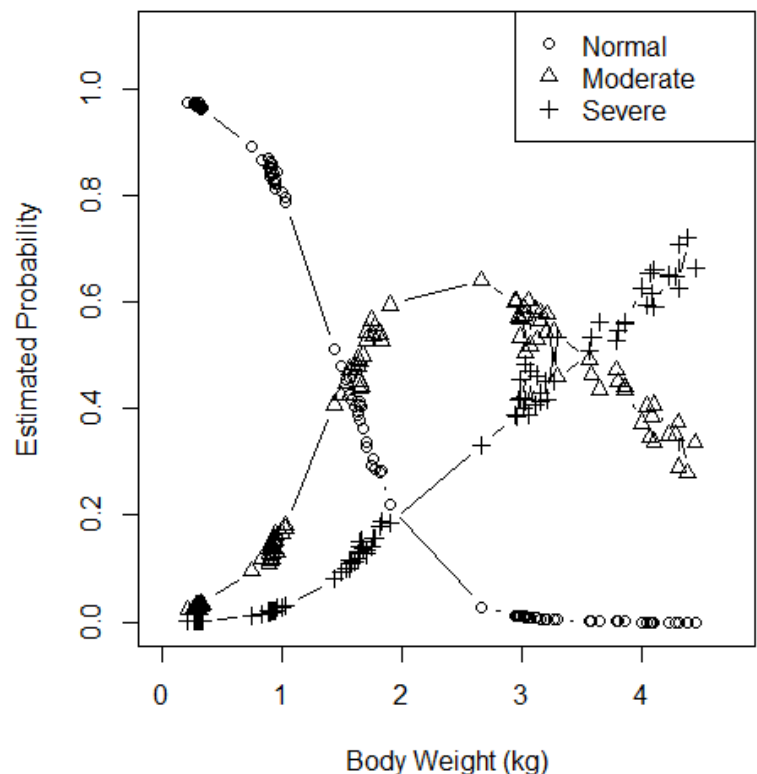

High nutrient density diet (HND)

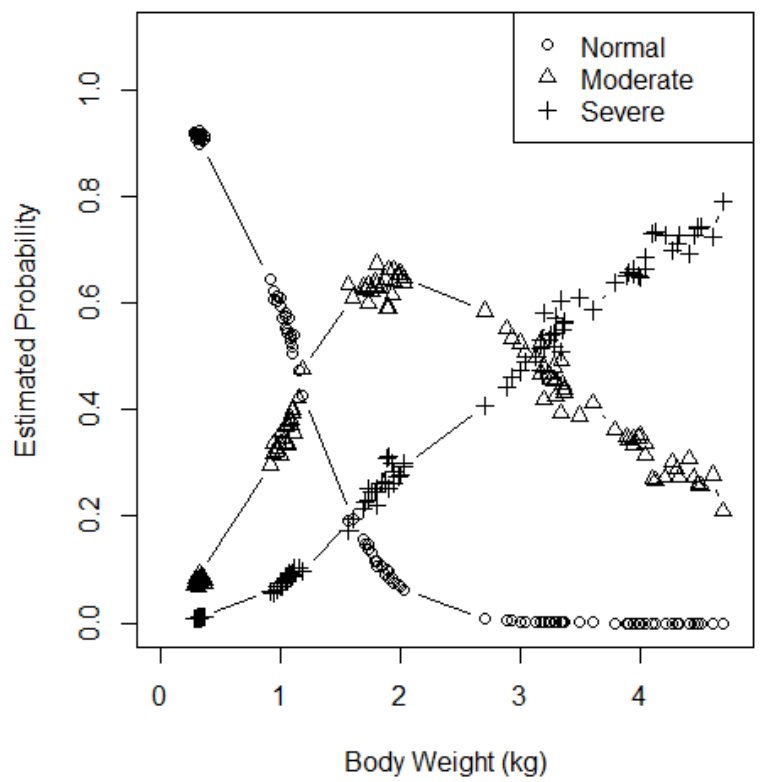

Figure 1: Probability of occurrence of white striping with respect to the body weight. (A) Values were polled in birds fed a low-energy (LED). (B) Values were polled in birds fed high-energy (HED) 
Citation: Kindlein L, Ferreira TZ, Driemeier D, Nascimento VP, Vieira SL, et al. (2017) Occurrence and Severity of White Striping in Broilers Until 50d of Age Fed with High and Low-Energy Diets: Body Weight, Histopathological Changes and Meat Quality. J Vet Sci Technol 8: 478. doi: $10.4172 / 2157-7579.1000478$

Page 5 of 8

\begin{tabular}{|c|c|c|c|c|c|c|c|c|}
\hline & \multirow{2}{*}{ WS degree ${ }^{1}$} & \multicolumn{2}{|c|}{ Treatments $^{1}$} & \multirow{2}{*}{ Mean \pm SEM } & \multicolumn{4}{|c|}{$P$-value ${ }^{\star \star}$} \\
\hline & & HED & LED & & BW & Diet & WS & Diet X WS \\
\hline \multirow{3}{*}{$\mathrm{pH}_{0}$} & NORM & $6.08 \pm 0.36$ & $6.20 \pm 0.59$ & $6.12 \pm 0.51^{a}$ & $<0.001$ & 0.19 & 0.002 & 0.21 \\
\hline & MOD & $6.49 \pm 0.42$ & $6.67 \pm 0.64$ & $6.57 \pm 0.53^{b}$ & & & & \\
\hline & SEV & $6.57 \pm 0.24$ & $6.52 \pm 0.20$ & $6.55 \pm 0.22^{\mathrm{ab}}$ & & & & \\
\hline \multirow{3}{*}{$\mathrm{pH}_{24}$} & NORM & $5.81 \pm 0.28$ & $5.72 \pm 0.29^{a}$ & $5.76 \pm 0.29$ & $<0.001$ & 0.32 & 0.38 & 0.04 \\
\hline & MOD & $6.06 \pm 0.36$ & $6.21 \pm 0.27^{\mathrm{b}}$ & $6.13 \pm 0.32$ & & & & \\
\hline & SEV & $6.26 \pm 0.36$ & $6.36 \pm 0.13^{a b}$ & $6.30 \pm 0.30$ & & & & \\
\hline \multirow{3}{*}{ Shear force $_{\text {raw }}$} & NORM & $2.58 \pm 0.77$ & $2.69 \pm 0.73$ & $2.68 \pm 0.70$ & $<0.001$ & 0.62 & 0.31 & 0.08 \\
\hline & MOD & $2.62 \pm 0.66$ & $2.79 \pm 0.65$ & $2.71 \pm 0.66$ & & & & \\
\hline & SEV & $2.90 \pm 0.66$ & $2.82 \pm 0.61$ & $2.86 \pm 0.64$ & & & & \\
\hline \multirow{3}{*}{ Shear force $_{\text {cooked }}$} & NORM & $3.65 \pm 0.87$ & $3.57 \pm 0.79$ & $3.61 \pm 0.95$ & $<0.001$ & 0.97 & 0.95 & 0.03 \\
\hline & MOD & $3.41 \pm 0.93$ & $3.41 \pm 0.91$ & $3.41 \pm 0.91$ & & & & \\
\hline & SEV & $3.44 \pm 0.81$ & $3.34 \pm 0.83$ & $3.39 \pm 0.82$ & & & & \\
\hline \multirow{3}{*}{$\mathrm{L}^{*}$} & NORM & $56.72 \pm 4.23$ & $57.89 \pm 4.56$ & $57.68 \pm 4.03$ & 0.14 & 0.89 & 0.56 & 0.71 \\
\hline & MOD & $57.68 \pm 4.18$ & $57.45 \pm 4.24$ & $57.56 \pm 4.15$ & & & & \\
\hline & SEV & $57.93 \pm 3.83$ & $58.24 \pm 4.37$ & $58.07 \pm 4.06$ & & & & \\
\hline \multirow{3}{*}{$a^{*}$} & NORM & $1.33 \pm 0.25$ & $1.31 \pm 0.22$ & $1.35 \pm 0.23$ & 0.8 & 0.19 & 0.49 & 0.56 \\
\hline & MOD & $1.38 \pm 0.22$ & $1.34 \pm 0.15$ & $1.36 \pm 0.19$ & & & & \\
\hline & SEV & $1.37 \pm 0.18$ & $1.29 \pm 0.20$ & $1.33 \pm 0.19$ & & & & \\
\hline \multirow{3}{*}{$b^{*}$} & NORM & $1.15 \pm 0.24$ & $1.17 \pm 0.29$ & $1.13 \pm 0.21$ & 0.81 & 0.68 & 0.92 & 0.81 \\
\hline & MOD & $1.06 \pm 0.27$ & $1.05 \pm 0.26$ & $1.06 \pm 0.26$ & & & & \\
\hline & SEV & $1.10 \pm 0.18$ & $1.07 \pm 0.19$ & $1.08 \pm 0.18$ & & & & \\
\hline
\end{tabular}

Multiple comparisons among dietary and white striping effects. When no interactions were present, treatments were compared directly whereas, when interactions were present, treatments were compared within each level of the other factor. The P-value of the multiple comparisons was adjusted with the single-step method (Hothorn et al.), where: ${ }^{A-B}$ Means within a row followed by different superscript letters differ significantly $(P \leq 0.05)$ and ${ }^{\text {a-b }}$ Means within a column followed by different superscript letters differ significantly $(P \leq 0.10)$.

${ }^{1}$ In this notation, NORM, MOD and SEV denote normal, moderate and severe white striping degrees (Kuttappan et al., 2012a) and HED and LED denote the high and low nutrient dietary treatments. $\mathrm{pH}_{0}$ and $\mathrm{pH}_{24}$ denote muscle $\mathrm{pH}$ at time 0 and $24 \mathrm{~h}$ post-mortem.

${ }^{* *}$ Analysis of variance table with $\mathrm{P}$-values of the general linear hypotheses of treatment and white striping effects. For each variable, the $\mathrm{P}$ values of each row are associated with one the four hypotheses $H_{0}: \beta=0, H_{0}: \alpha_{i}=0$, for all $\mathrm{i}, H_{0}: \delta_{j}=0$ for all $\mathrm{j}$ and $H_{0}:(\alpha \delta)_{i j}=0$ for all $\mathrm{i}$ and $\mathrm{j}$.

Table 4: Mean and SEM values of meat quality attributes of broiler breast meat classified as 3 degrees of white striping from birds feed two dietary treatments (HED and LED)*.

meat lie between 48 and 51, it indicated that the average luminosity of our breast muscles was higher than normal for all groups, however no significant difference $(P=0.56)$ was found between degrees of white striping. Kuttappan et al. [8], Petracci et al. [33] and Trocino et al. [34] also observed no differences in $\mathrm{L}^{*}$ values in breast meat samples with different degrees of white striping. These results are also in the same numerical range from those found by Qiao et al. [35] with values above 53 and below 46 indicate meat that is lighter and darker than normal, respectively.

Previous studies demonstrated that fillets affected by WS are more yellow than non-affected ones, probably due to the strong fibrotic response [8,36,37] however, Trocino et al. [34] found that the presence of WS decreased $\mathrm{a}^{*}$ and $\mathrm{b}^{*}$ indexes.

In general, white-striped breasts exhibit some minor differences in final $\mathrm{pH}$ and color indexes, not always consistent among studies $[34,36,38,39]$.

Also, there were significant differences in the values $\mathrm{SF}_{\text {raw }}$ and $\mathrm{SF}_{\text {cooked }}$ at different $\mathrm{BW}$ and ages $(P<0.001)$. but no significant difference between degrees of white striping and diets with regard to both $\mathrm{SF}_{\text {raw }}$ and $\mathrm{SF}_{\text {cooked }}$. Shear force on raw meat is manly reflecting background or collagen toughness, whereas shear force on cooked meat may be consider a measurement of myofibrillar toughness. In WS meat, the overall connective tissue increases to the detriment of the protein amount, which was found to be lower than normal meat [29].

In a study conducted by Kuttappan et al. [40] consumers indicated that fillets with severe WS look fattier and have a marbled appearance.
The occurrence of WS is negatively impacting the poultry processing industry, and the industry is facing great economic losses due to customer complaints about fillets affected by this myopathy [41]. Meat quality traits such as texture, color and $\mathrm{pH}$ can affect consumer preference for meat [42]. According to Kuttappan et al. [40], consumers are more likely to buy normal fillets without any white striations and over $50 \%$ of consumers indicated that they will probably not or definitely not buy moderate or severely white striped fillets.

\section{Histological results}

Figure 2 compares the histological lesions observed in breast muscles of broilers fed low or high-nutrient diets, and compares breasts with NORM, MOD, and SEV degrees of white striping. At $10 \mathrm{~d}$ of age, the breast muscles of all birds fed the LED diets had no histopathological alterations (Figure 2A), however some birds fed the HED diets had flocculate and hyaline necrosis of moderate multifocal myofibers, macrophage and heterophil infiltration, residual myofiber phagocytosis and some regenerating myofibers (Figure 2B). In this study, $20 \mathrm{~d}$-old birds from both dietary treatments (LED and HED) had breast muscles with white striping, but only birds fed the HED diets had breast muscles with SEV white striping and myopathy (Figure $2 \mathrm{C}$ ), indicating that growth rate was correlated with the severity of myopathy at the cellular level.

Histologically, in breast muscle of animals at $20 \mathrm{~d}$ of age, we observed hyaline and floccular scattered necrosis in myofibers, some with calcification, infiltration of macrophages, lymphocytes and a few heterophils, phagocytosis of residual myofibers, regenerating myocytes in some cases and sarcoplasmic vacuolization (Figure 2D). At 30 days 
Citation: Kindlein L, Ferreira TZ, Driemeier D, Nascimento VP, Vieira SL, et al. (2017) Occurrence and Severity of White Striping in Broilers Until 50d of Age Fed with High and Low-Energy Diets: Body Weight, Histopathological Changes and Meat Quality. J Vet Sci Technol 8: 478. doi: $10.4172 / 2157-7579.1000478$

of age, birds fed both diets showed all degrees of white striping severity, including normal breasts. So, in some skeletal muscles we found no histopathological changes (Figures 2E and 2F). At 40 and 50 d-old, we found no NORM breasts (no apparent striations), so that by $40 \mathrm{~d}$ of age, regardless of diet nutrient density or growth rate, all broiler breasts showed MOD or SEV white striping. This shows that at any age or stage of development, regardless of growth rate, the muscles presented histological changes that compromised the cellular structures, including myocytes with sarcoplasmic vacuolization (Figures $2 \mathrm{G}$ and $2 \mathrm{H}$ ).

Similarly to our histological results, Kutappan et al. [9] reported an increase in mean scores for degenerative or necrotic lesions, fibrosis, and lipidosis as the degree of white striping increased from NORM to SEV. Velleman et al. [32] found that until $42 \mathrm{~d}$ of age the morphological structure of the Pectoralis major muscle in growth-restricted birds was not well organized into muscle fiber bundles with distinct individual muscle fibers as observed in unrestricted birds. The muscle fibers of growth-restricted birds showed increased necrosis and larger and more extensive fat cell depots beginning at $28 \mathrm{~d}$ post-hatch (Figure 3 ).

Our results indicated that growth rate was correlated with the severity of myopathy at the cellular level. This correlation also was presented by Wilson et al. [43] that observed positive correlations between age, growth rate and plasma creatine kinase (CK) concentrations and the incidence of damaged muscle in birds. Those authors concluded that broiler muscles outgrow their life support systems, which negatively affects myocellular integrity. Furthermore, our results in breast muscle of animals at $20 \mathrm{~d}$ of age are in accordance to Wilson et al. [43], who found degenerative changes that included scattered and focal necrosis and infiltration of necrotic areas by mononuclear cells in damaged skeletal muscle of birds.

In another study, Kuttappan et al. [8] concluded that the occurrence of MOD and SEV degrees of white striping was histologically characterized by chronic myopathic lesions like loss of cross striations, mild mineralization, lipidosis, and fibrosis. Moreover, similar to our results, Kuttappan et al. [11] found floccular and vacuolar degeneration, mononuclear cell infiltration, and interstitial inflammation. The changes at any age or stage of development observed in our study indicated the impairment of cellular structures such as sarcoplasmic reticulum vacuolization that are also characteristic of exercise-induced muscle injury [44], supporting the notion that the muscles exceeded their support systems.

According to Table 5, in relation to capillary density (CD), capillary to fiber ratio (C:F) and intercapillary distance (IcD) there was no statistical difference to CD between the degrees of WS on 20,30 and 40-days of age. The values of C:F was lower in SEV compared to NORM breasts at $40 \mathrm{~d}$, however higher values were observed on SEV birds to IcD at 20,30 and $40 \mathrm{~d}$, suggesting a lower capillary supply and oxygenation on the breast fillets affected with this myopathy.

This myopathy has been associated with an increased muscle hypertrophy of fast-growing chickens, witch brings about a reduced capillary supply that could result in a decreased source of nutrients and oxygen and slower removal lactic acid from breast muscles, which ultimately may lead to muscle damage $[2,45]$.

\section{Conclusions}

The results of this study revealed that at $10 \mathrm{~d}$ of age, $2.27 \%$ of the birds showed some degree of WS and at 20 and $30 \mathrm{~d}$ of age the occurrence of WS was higher in birds fed HED than birds fed LED diets. The odds of having moderate rather than normal or severe

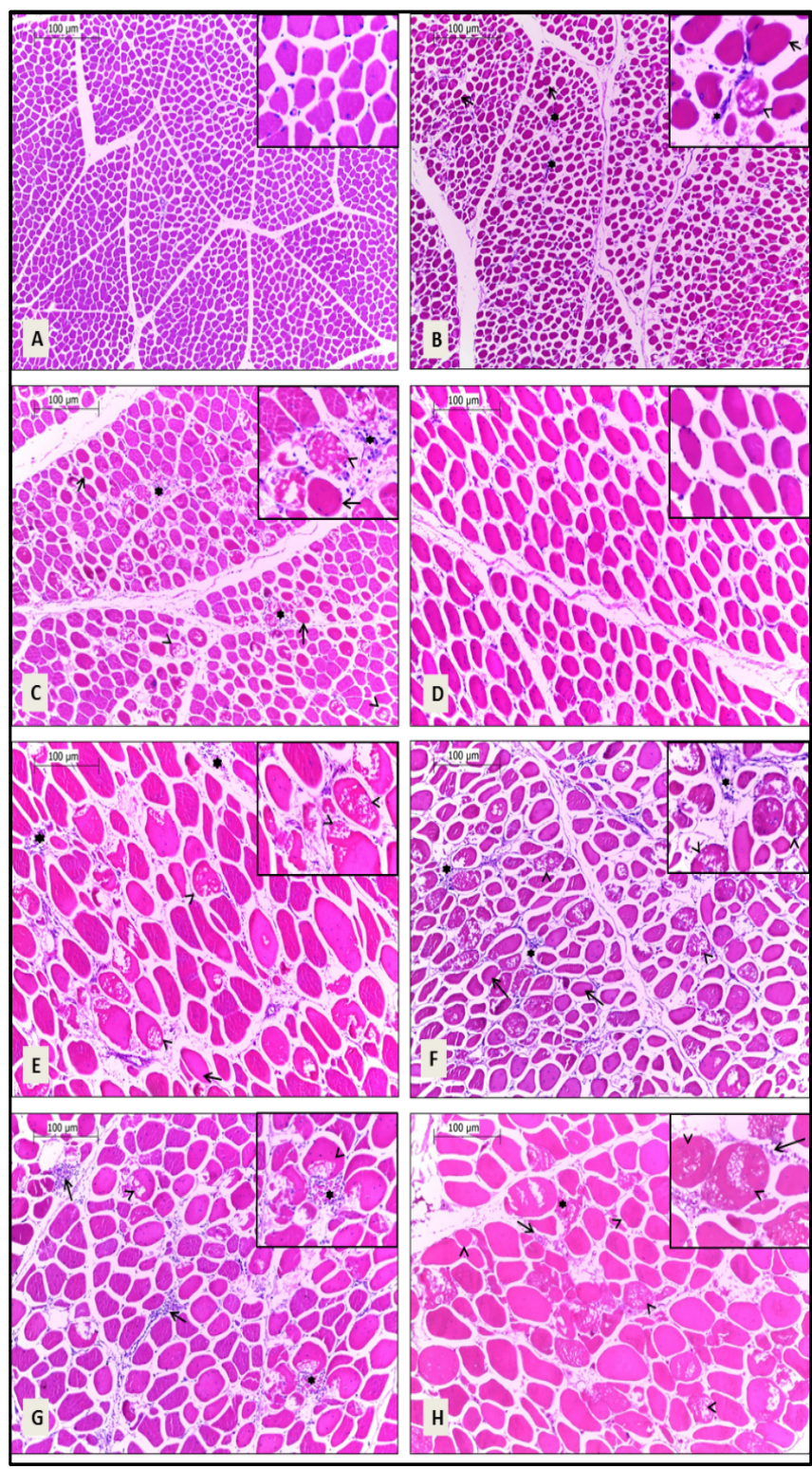

Figure 2: Morphological structure of muscle fibers in broilers: (A) at $10 \mathrm{~d}$-old fed LED-diet classified as normal white striping (WS) (without myopathy on macroscopic observation) and (B) HED-diet (B) classified as moderate WS: flocculate necrosis (arrowhead) and hyaline necrosis of myofiber (arrow) moderate multifocal, discrete infiltration of macrophages and a few heterophils (asterisk). (C) at $20 \mathrm{~d}$-old fed HED-diet classified as severe WS: flocculate (arrowhead) and hyaline (arrow) necrosis of diffuse myofibers, diffuse infiltration of macrophages around myofibers necrotics, lymphocytes and few heterophils (asterisk), myocytes with sarcoplasmic vacuolization. Inset (40X): flocculate necrosis (arrowhead) and hyaline necrosis of myofiber (arrow) moderate multifocal, infiltration of macrophages around myofibers necrotics, lymphocytes and few heterophils (asterisk). (D) at $30 \mathrm{~d}$-old fed HED-diet classified as normal WS, without histological change. (E, F) at 40 d-old fed HED-diet (E) or LED-diet (F) classified as severe WS: flocculate (arrowhead) and hyaline (arrow) necrosis of myofibers diffuse, and infiltration of macrophages (asterisk), phagocytosis of residual myofibers. Inset (40X): flocculate (arrowhead) and hyaline necrosis of myofibers diffuse, and infiltration of macrophages (asterisk), phagocytosis of residual myofibers. ( $\mathrm{G}, \mathrm{H}$ ) at $50 \mathrm{~d}$-olf fed HED-diet classified as moderate (G) and severe $(H)$ WS. (G) Flocculate and hyaline moderate-multifocal necrosis (arrowhead) with interstitial infiltration of macrophages (arrow) and phagocytosis of necrotics myofibers (asterisk). $(\mathrm{H})$ Flocculate and hyaline necrosis of diffuse myofibers (arrowhead) with infiltration of macrophages (asterisk). HE. 
Citation: Kindlein L, Ferreira TZ, Driemeier D, Nascimento VP, Vieira SL, et al. (2017) Occurrence and Severity of White Striping in Broilers Until 50d of Age Fed with High and Low-Energy Diets: Body Weight, Histopathological Changes and Meat Quality. J Vet Sci Technol 8: 478. doi: $10.4172 / 2157-7579.1000478$

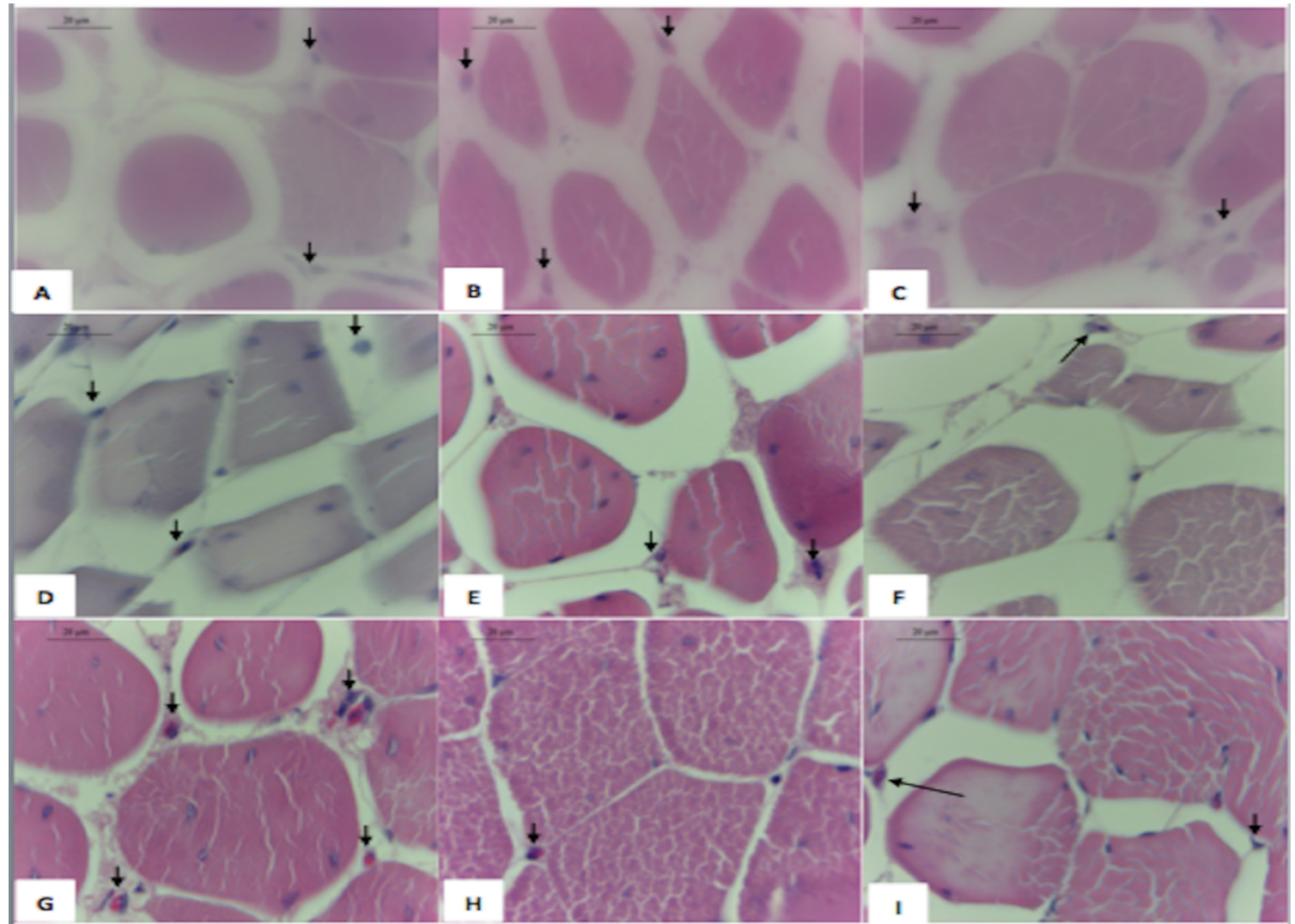

Figure 3: Histological evaluation of muscle fibers in broilers with capillaries (black arrows): (A) 20 d-old classified as normal white striping (WS); (B) 20 d-old classified as moderate WS; (C) 20 d-old classified as severe WS; (D) 30 d-old classified as normal white striping (WS); (E) 30 d-old classified as moderate WS; (F) 30 d-old classified as severe WS; (G) 40 d-old classified as normal white striping (WS); (H) 40 d-old classified as moderate WS; (I) 40 d-old classified as severe WS. HE. 1000x.

\begin{tabular}{|c|c|c|c|c|}
\hline Age & WS degree ${ }^{1}$ & $\mathrm{CD}\left(\mathrm{mm}^{2}\right)$ & IcD (mm) & C:F \\
\hline \multirow{4}{*}{20} & NORM & 12,667 & $0,300^{c}$ & 0,414 \\
\hline & MOD & 12,333 & $0,320^{\mathrm{b}}$ & 0,412 \\
\hline & SEV & 11,333 & $0,340^{\mathrm{a}}$ & 0,382 \\
\hline & $p$-value & 0,888 & $<0,0001$ & 0,902 \\
\hline \multirow{4}{*}{30} & NORM & 10,000 & $0,360^{\mathrm{b}}$ & 0,303 \\
\hline & MOD & 10,333 & $0,360^{\mathrm{b}}$ & 0,309 \\
\hline & SEV & 7,333 & $0,420^{a}$ & 0,340 \\
\hline & $p$-value & 0,069 & $<0,0001$ & 0,818 \\
\hline \multirow{4}{*}{40} & NORM & 10,333 & $0,360^{\mathrm{b}}$ & $0,446^{a}$ \\
\hline & MOD & 11,000 & $0,340^{\circ}$ & $0,390^{\mathrm{ab}}$ \\
\hline & SEV & 7,333 & $0,420^{\mathrm{a}}$ & $0,254^{b}$ \\
\hline & $p$-value & 0,306 & $<0,0001$ & 0,009 \\
\hline
\end{tabular}

${ }^{1}$ In this notation, NORM, MOD and SEV denote normal, moderate and severe white striping degrees (Kuttappan et al).

${ }^{a-c}$ Means followed by different letters in the same column are significantly different $(P<0.05)$.

Table 5: Values of capillary density (CD), intercapillary density (ICD) and capillary to fiber ratio (C:F) of broiler breast fillets affected by different degrees of white striping and processed at 20,30 and $40 \mathrm{~d}$.

white striping were multiplied by $23 \mathrm{X}$ and $51 \mathrm{X}$, respectively, for each $\mathrm{kg}$ increase in $\mathrm{BW}$ and the odds of having moderate white striping rather than normal white striping for the low diet was 0.40 times the odds for the high diet. There was no differences $(\mathrm{P}>0.05)$ in the $\mathrm{L}^{*}$, $\mathrm{a}^{*}$, and $\mathrm{b}^{*}$ values for meat or among different degrees of WS as well as between dietary treatments; however, carcass characteristics varied by age or carcass weight. Overall, white striping was more prevalent in broilers fed high as compared to low energy diets, and involved histopathological changes in myofibers, with muscle fibers showing sarcoplasmic reticulum vacuolization, a higher intercapillary distance and a reduced capillary to fiber ratio, suggesting loss of integrity of the cell structure, that was seen in birds fed both diets (low and high nutrient densities) after $30 \mathrm{~d}$ of age and lower oxygenation.

\section{Acknowledgements}

This work was supported by the Brazilian Federal Agency for Support and Evaluation of Graduate Education (CAPES); National Counsel of Technological and Scientific Development (CNPQ) under Grant [Number 482923]. 
Citation: Kindlein L, Ferreira TZ, Driemeier D, Nascimento VP, Vieira SL, et al. (2017) Occurrence and Severity of White Striping in Broilers Until 50d of Age Fed with High and Low-Energy Diets: Body Weight, Histopathological Changes and Meat Quality. J Vet Sci Technol 8: 478. doi: $10.4172 / 2157-7579.1000478$

Page 8 of 8

\section{References}

1. Petracci M, Mudalal S, Soflia F, Cavani C (2015) Meat quality in fast-growing broiler chickens. World's Poult Sci J 71: 363-374.

2. Cruz RFA, Vieira SL, Kindlein L, Kipper M, Cemin HS, et al. (2017) Occurrence of white striping and wooden breast in broilers fed grower and finisher diets with increasing lysine levels. Poult Sci 96: 501-510.

3. Radaelli G, Piccirillo A, Birolo M, Bertotto D, Gratta G, et al. (2017) Effect of age on the occurrence of muscle fiber degeneration associated with myopathies in broiler chickens submitted to feed restriction. Poult Sci 96: 309-319.

4. Macrae VE, Mahon M, Gilpin S, Sandercock DA, Mitchell MA (2006) Skeletal muscle fibre growth and growth associated myopathy in the domestic chicken (Gallus domesticus). Br Poult Sci 47: 264-272.

5. Duclos MJ, Berri C, Le Bihan-Duval E (2007) Muscle growth and meat quality. J Appl Poult Res 16: 107-112.

6. Zhang L, Zhang HJ, Qiao X, Yue HY, Wu SG, et al. (2012) Effect of monochromatic light stimuli during embryogenesis on muscular growth, chemical composition, and meat quality on breast muscle in male broilers. Poult Sci 91: 1026-1031.

7. Kuttappan VA, Goodgame SD, Bradley CD, Mauromoustakos A, Hargis BM, et al. (2012) Effect of different levels of dietary vitamin E (DL-a-tocopherol acetate) on the occurrence of various degrees of white striping on broiler breast fillets. Poult Sci. 91: 3230-3235.

8. Kuttappan VA, Brewer VB, Mauromoustakos A, Mckee SR, Emmert JL, et al. (2013) Estimation of factors associated with the occurrence of white striping in broiler breast fillets. Poult Sci 92: 811-819.

9. Kuttappan VA, Shivaprasad HL, Shaw DP, Valentine BA, Hargis BM, et al (2013) Pathological changes associated with white striping in broiler breast muscles. Poult Sci 92: 331-338.

10. Ferreira TZ, Casagrande RA, Vieira SL, Driemeier D, Kindlein L (2014) An investigation of a reported case of white striping in broilers. J Appl Poult Res 23: 748-753.

11. Kuttappan VA, Brewer VB, Apple JK, Waldroup PW, Owens CM (2012) Influence of growth rate on the occurrence of white striping in broiler breast fillets. Poult Sci 91: 2677-2685.

12. Bailey RA, Watson KA, Bilgili SF, Avendano S (2015) The Genetic basis of pectoralis major myopathies in modern broiler chicken lines. Poult Sci 94 : 2870-2879.

13. Dubowitz V, Sewry CA, Oldfors A (2013) Muscle biopsy-A practical approach 4th edn, London: Saunders Elsevier, p: 572

14. Kuttappan VA, Hargis BM, Owens CM (2016) White striping and wooden breast myopathies in the modern poultry industry: a review. Poult Sci 95: 2724-2733.

15. Rostagno HS, Albino LFT, Donzele JL, Gomes PC, Oliveira RF, et al. (2011) Brazilian tables for poultry and swine: composition of foods and nutritional requirements. 3rd edn. Viçosa, Brazil, p: 252.

16. Krogh A (1929) The number and distribution of capillaries in muscles with calculations of the oxygen pressure head necessary for supplying the tissue. Physiol 52: 409-415.

17. Sosnicki AA, Cassens RG, Vimini RJ, Greaser ML (1991) Distribution of Capillaries in Normal and Ischemic Turkey Skeletal Muscle. Poult Sci 70: 343-348.

18. Chrystall B, Culioli J, Honikel KO, Möller AJ, Purslow P, et al. (1994) Recommendation of reference methods for assesment of meat tenderness. Proceedings of the 40 th International Congress of Meat Science and Technology (ICoMST), The Hague, Netherlands, pp: 1-7.

19. AMSA (1995) Research guidelines for cookery, sensory evaluation and instrumental tenderness measurements of fresh meat. Chicago, IL: American Meat Science Association and National Live Stock and Meat Board.

20. Liu Y (2004) Principal component analysis of physical, color, and sensory characteristics of chicken breasts deboned at two, four, six, and twenty-four hours post-mortem. Poult Sci 83: 101-108.

21. Thomas A, O'Hara B, Ligges U, Sturtz S (2006) Making BUGS open. R News 6: $12-17$

22. Thomas $A$ (2006) The BUGS language. R News 6: 17-21.

23. Gelman A, Rubin, DB (1992) Inference from iterative simulation using multiple sequences. Statistic Sci 7: 457-472.

24. Pinheiro J, Bates DM (2000) Mixed effects models in S and SPLUS. Statistics and Computing. Springer, New York, NY.

25. R Core Team (2013) R: A language and environment for statistical computing R Foundation for Statistical Computing, Vienna, Austria.

26. Pinheiro J, Bates D, Debroy S, Sarkar D (2013) R Development Core Team nlme: Linear and Nonlinear Mixed Effects Models. R package version 3.1-113.

27. Hothorn T, Bretz F, Westfall $P$ (2008) Simultaneous inference in general parametric models. Biom J 50: 346-363.

28. Petracci M, Sirri F, Mazzoni M, Meluzzi A (2013) Comparison of breast muscle traits and meat quality characteristics in 2 commercial chickens hybrids. Poult Sci 92: 2438-2447.

29. Petracci M, Mudalal S, Babini E, Cavani C (2014) Effect of white striping on chemical composition and nutritional value of chicken breast meat. Ital J Anim Sci 13: 179-183.

30. Fernandez X, Forslid A, Tornberg E (1994) The effect of high postmortem temperature on the development of pale, soft, and exudative pork: Interaction with ultimate $\mathrm{pH}$. Meat Sci 37: 133-147.

31. Woelfel RL, Owens CM, Hirschler EM, Martinez-Dawson R, Sams AR (2002) The characterization and incidence of pale, soft, and exudative broiler meat in a commercial processing plant. Poult Sci 81: 579-584.

32. Velleman SG, Nestor KE, Coy CS, Harford I, Anthony NB (2010) Effect of Posthatch Feed Restriction on Broiler Breast Muscle Development and Muscle Transcriptional Regulatory Factor Gene and Heparan Sulfate Proteoglycan Expression. Poult Sci 9: 417-425.

33. Petracci M, Mudalal S, Bonfiglio A, Cavani C (2013) Occurrence of white striping and its impact on breast meat quality in broiler chickens. Poult Sci 92 1670-1675.

34. Trocino A, Piccirillo A, Birolo M, Radaelli G, Bertotto D, et al. (2015) Effect of genotype, gender and feed restriction on growth, meat quality and the occurrence of white striping and wooden breast in broiler chickens. Poult Sci 94: 2996-3004.

35. Qiao M, Fletcher DL, Northcutt JK, Smith DP (2002) The relationship between raw broiler breast meat color and composition. Poult Sci 81: 422-427.

36. Petracci M, Sirri F, Mazzoni M, Meluzzi A (2013) Comparison of breast muscle traits and meat quality characteristics in 2 commercial chicken hybrids. Poult Sci 92: 2438-2447.

37. Dalle Zotte A, Tasoniero G, Russo E, Longoni C, Cecchinato M (2015) Impact of coccidiosis control program and feeding plan on white striping prevalence and severity degree on broiler breast fillets evaluated at three growing ages. Poult Sci 94: 2114-2123.

38. Mudalal S, Lorenzi M, Soglia F, Cavani C, Petracci M (2014) Implications of white striping and wooden breast abnormalities on quality traits of raw and marinated chicken meat. Animal 9: 728-734

39. Mazzoni M, Petracci M, Meluzzi A, Cavani C, Clavenzani P, et al. (2015) Relationship between pectoralis major muscle histology and quality traits of chicken meat. Poult Sci 94: 123-130.

40. Kuttappan VA, Lee Y, Erf GF, Meullenet JF, Owens CM (2012) Consumer acceptance of visual appearance of broiler breast meat with varying degrees of white striping. Poult Sci 91: 1240-1247.

41. Tijare V, Yang F, Kuttappan V, Alvarado C, Coon C, et al. (2016) Meat Quality of Broiler Breast fillets with White Striping and Woody Breast Muscle Myopathies. Poult Sci 0: 1-7.

42. Fanatico AC, Pillai PB, Cavitt LC, Owens CM, Emmert JL (2005) Evaluation of Slower-Growing Broiler Genotypes Grown with and Without Outdoor Access: Growth Performance and Carcass Yield. Poult Sci 84: 1321-1327.

43. Wilson BW, Nieberg PS, Buhr RJ (1990) Turkey muscle growth and foca myopathy. Poult Sci 69: 1553-1562.

44. Belcastro AN, Shewchuk LD, Raj DA (1998) Exercise-induced muscle injury: a calpain hypothesis. Mol. and Cel Bioch 179: 135-145.

45. Hoving-Bolink AH, Kranen RW, Klont RE, Gerritsen CLM, de Greef KH (2000) Fibre area and capillary supply in broiler breast muscle in relation to productivity and ascites. Meat Sci 56: 397-402. 